\title{
A Preliminary Study: Esterification of Free Fatty Acids (FFA) in Artificially Modified Feedstock Using Ionic Liquids as Catalysts
}

\author{
Nurul Asmawati Roslan ${ }^{1}$, Mohammad Haniff Che Hasnan ${ }^{1}$, Norhayati Abdullah ${ }^{1}$, \\ Syamsul Bahari Abdullah ${ }^{1}$, Sumaiya Zainal Abidin ${ }^{1,2^{*}}$ \\ ${ }^{1}$ Faculty of Chemical Engineering \& Natural Resources, Universiti Malaysia Pahang, \\ 26300 Gambang, Pahang, Malaysia \\ ${ }^{2}$ Centre of Excellence for Advanced Research in Fluid Flow (CARIFF), Universiti Malaysia \\ Pahang, 26300 Gambang, Pahang, Malaysia
}

Received: 21 ${ }^{\text {st }}$ January 2016; Revised: $2^{\text {th }}$ February 2016; Accepted: $6^{\text {th }}$ March 2016

\begin{abstract}
The exploration of non-edible oils as a feedstock has been positively affect the economic viability of biodiesel production. Due to the high level of free fatty acid (FFA) in non-edible oils, esterification is needed to remove the acidity to the minimum level before base-catalyzed transesterification. In this study, 1-hexyl-3-methylimidazolium hydrogen sulphate (HMIMHSO 4$)$ was self-synthesized and compared with the commercialized ionic liquid, 1-butyl-3-methylimidazolium hydrogen sulphate $\left(\mathrm{BMIMHSO}_{4}\right.$ ). $\mathrm{HMIMHSO}_{4}$ and $\mathrm{BMIMHSO}_{4}$ were characterized by ${ }^{1} \mathrm{H}$ NMR prior to use in the esterification reaction. The reaction was carried out in a batch reactor and variables such as types of alcohol, oil: alcohol molar ratio, temperature and types of stirring were investigated. The highest conversion for each catalyst was achieved using ethanol as a solvent at the condition of $343 \mathrm{~K}$ reaction temperature, $12: 1$ alcohol to oil ratio in $8 \mathrm{~h}$ reaction time. $\mathrm{BMIMHSO}_{4}$ showed higher conversion (98\%) as compared to $\mathrm{HMIMHSO}_{4}$ with only $82 \%$ conversion. Clearly, $\mathrm{BMIMHSO}_{4}$ shows considerable potential to reduce the FFA in the feedstock as it is exhibit excellent catalytic activity due to lower alkyl chain of BMIMHSO $_{4}$ compared to HMIMHSO 4 . Copyright (C 2016 BCREC GROUP. All rights reserved
\end{abstract}

Keywords: Biodiesel; Free Fatty Acids; Acidified Oil; Esterification; Ionic Liquid

How to Cite: Roslan, N.A., Che Hasnan, M.H., Abdullah, N., Abdullah, S.B., Abidin, S.Z. (2016). A Preliminary Study: Esterification of Free Fatty Acids (FFA) in Artificially Modified Feedstock Using Ionic Liquids as Catalysts. Bulletin of Chemical Reaction Engineering \& Catalysis, 11 (2): 182-190 (doi:10.9767/bcrec.11.2.549.182-190)

Permalink/DOI: http://dx.doi.org/10.9767/bcrec.11.2.549.182-190

\section{Introduction}

With the development of the global economy and increasing of environmental pollution problems, the energy crisis becomes steadily more serious. The environmental problems caused by

* Corresponding Author.

E-mail: sumaiya@ump.edu.my (S.Z. Abidin)

Tel: +6095492890, Fax: +6095492889 the use of fossil fuels also raised a great concern as the carbon dioxide produced from the fossil fuel contributes to the greenhouse effect. This has prompted many researchers to search for efficient, safe and renewable energy sources. Biodiesel, a monoalkyl ester of fatty acids has recently gained considerable attention as an alternative energy sources [1]. It was reported that the use of $100 \%$ pure biodiesel 
could reduce carbon dioxide by $78.5 \%$ as compared to the petroleum-based diesel [2].

Biodiesel can be produced from transesterification of triglycerides or esterification of free fatty acids (FFA). Alcohols, such as methanol and ethanol, are usually used as the acyl acceptor due to the wide availability and low in price [3]. Non-edible or low costs feedstock usually contain high FFA, which needs to be reduced to less than $1 \%$ to prevent saponification of FFA from occurring, especially when alkali catalysts were employed [4]. Thus, esterification became one of the important pre-treatment processes in biodiesel synthesis. Conventional esterification method was conducted in the presence of homogeneous acid catalyst [5-7]. However, the utilization of these catalysts raised few drawbacks (i.e. equipment corrosion problems and generation of acidic wastewater from the neutralizing process [8]). Since then, different types of catalysts have been developed and investigated in order to obtain higher biodiesel yield. Different type of heterogeneous catalyst has been investigated in the esterification reaction such as sulfated zirconia [9, 10], heteropolyacids [11], and ion-exchange resins [12]. These catalysts successfully solved the problems of equipment corrosion and environmental pollution. However, the preparation of these catalysts is relatively complicated and they are difficult to be recycled, hence contribute to higher production cost. Therefore, it is necessary to develop environmentally friendly, efficient and recyclable catalysts that able to produce an economical esterification process.

In recent years, there have been growing interests in the usage of ionic liquids (ILs) as catalysts in biodiesel synthesis. ILs are salts consisting of organic cations and inorganic or organic anions, which presence in liquid form at room temperature or at relatively low temperature $\left(<100{ }^{\circ} \mathrm{C}\right)$. Attractive characteristics offered by IL are by having a high thermal stability, negligible vapor pressures and excellent solubility and miscibility with reactants. The uniqueness of this catalyst lays on the acidity and basicity level flexibility as it can be tailored using different types of cations and anions [13]. The acidic or alkaline behavior depends on the type of anion attached to the bulky cation, which can be from Brønsted acid, Lewis acid or alkali groups. The utilization of ILs as catalysts in biodiesel synthesis has been studied recently [1, 8, 13]. Fang et al. [14] conducted esterification of FFA using dicationic ILs as catalyst. They and found that this type of catalyst performed better in terms of catalytic activity as compared to monocationic ILs.
Guo et al. [15] studied on the performance of ILs in the transesterification of biodiesel using Jatropha oil. They found that the addition of metal chlorides to the ILs increases the catalyst's acidic sites which simultaneously enhance the transesterification reaction.

Recently, Brønsted acidic ILs has become one of the potential catalysts for green biodiesel synthesis. The catalytic performance was proven to be comparable and better compared to conventional catalysts. 1-butyl-3methylimidazolium hydrogen sulfate ( $\mathrm{BMIMHSO}_{4}$ ) and 1-methyl-3methylimidazolium hydrogen sulfate $\left(\mathrm{HMIMHSO}_{4}\right)$ are Brønsted acidic ILs with acidic counterion, which influence its catalytic performance in reactions. Both of the ILs prevails as the catalyst with a good catalytic activity in esterification [8, 16]. Elsheikh et al. [16] used different types of Brønsted imidazolium ILs as catalysts in biodiesel production. They found that the higher acidity of $\mathrm{BMIMHSO}_{4}$ resulted in the highest conversion of crude palm oil (CPO) in a two-stage biodiesel process. The conversion of FFA in the CPO was reduced to $91.2 \%$ in the pre-treatment step prior to transesterification process.

In this paper, $\mathrm{HMIMHSO}_{4}$ and $\mathrm{BMIMHSO}_{4}$ were used as catalysts in the esterification of FFA using simulated used cooking oil (SUCO) as the feedstock. The reaction was carried out in a batch reactor and variables such as types of alcohol, oil to alcohol molar ratio, temperature and types of stirring have been investigated.

\section{Materials and Methods}

\subsection{Chemicals}

1-hexyl-3-methylimidazolium chloride (99\%), 1-butyl-3-methylimidazolium hydrogen sulfate (95\%), $p$-naphtolbenzein (analytical grade), sulphuric acid (99\%), trimethyl-1pentene $(97.4 \%)$, potassium hydroxide and oleic acid (88\%) were purchased from Sigma Aldrich Malaysia. Ethanol, butanol, propanol, toluene and acetonitrile with $99 \%$ purity were purchased from Fisher Scientific Malaysia. All solvents were analytical grade and used as supplied.

\subsection{Preparation of simulated used cook- ing oil (SUCO)}

The simulated used cooking oil (SUCO) was prepared by mixing the oleic acid and virgin palm oil (refined palm olein) to produce feedstock with $6 \%$ of FFA content. The solution 
were mixed in the conical flask and stirred by using magnetically stirred for 10 minutes. The SUCO was then tested for its acid value using titration method of ASTM D974. The acid value was approximately $12.63 \mathrm{mg} \mathrm{KOH} / \mathrm{g}$. Usually, the average value of FFA content in used cooking oil from industrial or house hold cooking oil is between $5 \%$ and $15 \%$ [17].

\subsection{Ionic liquid preparation}

A 1-hexyl-3-methylimidazolium chloride (HMIMCl) was dissolved in anhydrous acetronitrile in a $250 \mathrm{~mL}$ round bottom flask fitted with reflux condenser, magnetic stirrer and under nitrogen purge. The reaction was kept under cold condition and vigorous stirring. Then, concentrated sulphuric acid $\left(\mathrm{H}_{2} \mathrm{SO}_{4}\right)$ was slowly added to the mixture. The mixture was stirred continuously to ensure all the components are completely reacted. For immediate removal of $\mathrm{HCl}$ from the reaction phase, $\mathrm{N}_{2}$ gas was used to flush it. Then, the Brønsted ionic liquid, 1hexyl-3-methylimidazolium hydrogen sulphate $\left(\mathrm{HMIMHSO}_{4}\right)$ was washed several times with trimethyl-1-pentene and dried in vacuum for 6 h. It was sent for H-NMR analysis to determine the purity of the synthesized ILs. While $\mathrm{BMIMHSO}_{4}$ was used as received.

\subsection{Esterification of UCO}

The esterification reactions were carried out using a batch reactor in a $250 \mathrm{~mL}$ three-neck flask attached to a reflux condenser. A programmable temperature controller was used to monitor the reaction temperature. A specified amount of SUCO and alcohol was added to the reactor and the stirring and heating of the reaction mixtures were started. When the reaction mixtures reached the desired temperature, a known amount of catalyst was added and this time was taken as the zero time for the reaction. The experiments were carried out for $8 \mathrm{~h}$ with a constant stirring rate. The sample tube was fitted with syringe to withdraw the sample. The samples were taken periodically from the reactor for FFA analysis.

\subsection{Determination of acid number}

The acid numbers of the samples were determined according to the ASTM D974 standard method, which is described as follows. Firstly, approximately $2 \mathrm{~g}$ of sample was weighted and dissolved in $100 \mathrm{~mL}$ of a titration solution of toluene, 2-propanol and water with a volume ratio of 100:99:1. The mixture was then titrated potentiometrically with alcoholic $\mathrm{KOH}$ solution.
The acid number was the quantity (in $\mathrm{mg}$ ) of $\mathrm{KOH}$ per $1 \mathrm{~g}$ of sample required to titrate the sample to its neutral point. The equation used for the acid number determination is presented in Equation (1).

$$
N_{\text {acid }}=56.1 \times M \frac{A-B}{W}
$$

where: $M$ is a concentration of $\mathrm{KOH}, A$ is a volume of $\mathrm{KOH}$ used to reach the neutral point, $B$ is the volume corresponding to the blank titration and $W$ is the weight of the mass of the sample.

\subsection{Determination of $\%$ conversion of FFA}

The conversion of the FFA was defined as the fraction of FFA that reacted during the esterification process with the alcohol. The conversion of FFA (\% FFA) was determined from the acid number ratio using the Equation (2).

$$
\% F F A=\frac{A-B}{w} \times N \times 28.2
$$

where: $A$ is a volume in $\mathrm{ml}$ of titration solution, $B$ is the volume in $\mathrm{ml}$ of the blank, $N$ is a normality of the titration solution and $w$ is the weight of the sample of oil in grams.

\section{Results and Discussion}

\section{1. ${ }^{1} \mathrm{H}$ NMR results of 1-hexyl-3- methylimidazolium hydrogen sulfate (HMIMHSO 4 )}

The ionic liquid used in this work were synthesized and characterized by ${ }^{1} \mathrm{H}$ NMR before using as a catalyst for biodiesel production. The results as shown below:

Spectroscopic analysis: ${ }^{1} \mathrm{H}$ NMR $(271.2 \mathrm{~Hz} / \mathrm{cm}$, DMSO): $\delta=0.84-0.9$ (3H, q), $1.26(6 \mathrm{H}, \mathrm{s}), 1.78-$ $1.82(2 \mathrm{H}, \mathrm{q}), 4.19-4.22(2 \mathrm{H}, \mathrm{t}), 7.79-7.86(2 \mathrm{H}, \mathrm{q})$.

From the ${ }^{1} \mathrm{H}$ NMR results, 98\% purity of $\mathrm{HMIMHSO}_{4}$ was obtained. The purity of $\mathrm{BMIMHSO}_{4}$ was $98 \%$ while purchasing and was used as received.

\subsection{Studies on the effect of different variables in esterification reaction}

\subsubsection{Effect of different IL catalysts on the esterification of SUCO with ethanol}

The esterification reaction is started when the fatty acid accepts a proton $\left(\mathrm{H}^{+}\right)$from proton donor (catalyst). Then, alcohol molecule attacks the protonated carbonyl group to give a tetrahedral intermediate. Proton is lost at one oxygen atom and gained at another to form an- 
other intermediate and further loses a molecule of water to gives a protonated ester. Finally, a proton is transferred to a water molecule to give the ester [18]. Catalyst is required by the esterification to accelerate the process by promoting the protonation of carbonyl group on fatty acid group. Two ILs were chosen as catalyst and tested in this present study to reduce the FFA content in the SUCO. The activity of the IL catalyst is closely related to its acidity and its solubility towards the substrate. During the initial stage of the esterification reaction, the acidity of the IL plays an important role in the reaction and was significantly dependent on the anion characteristics of the IL. In addition, the cation of the IL also plays a crucial role in the reaction because the hydrophilicity of the IL can be tuned mainly by the cation. This affects the miscibility of the IL with the ester product, the degree of phase separation, and the reaction efficiency. $\mathrm{HMIMHSO}_{4}$ and $\mathrm{BMIMHSO}_{4}$ were tested in this study and gave the results depicted in Figure 1.

As can be seen in Figure 1, both of the catalysts showed a good conversion of FFA in SUCO with the optimum reaction conditions. However, $\mathrm{BMIMHSO}_{4}$ showed the highest catalytic activity and gives the highest conversion of $97 \%$ after reaction for $7 \mathrm{~h}$. Meanwhile, $\mathrm{HMIMHSO}_{4}$ able to reduce $82 \%$ of FFA in the first $7 \mathrm{~h}$. It was found that the rate of reaction of $\mathrm{HMIMHSO}_{4}$ is much lower compared to the $\mathrm{BMIMHSO}_{4}$. A similar statements reported and cited in literatures [19, 20, 21]. The ability to donate the electron of alkyl group increases with increasing the alkyl chain. Thus, it will

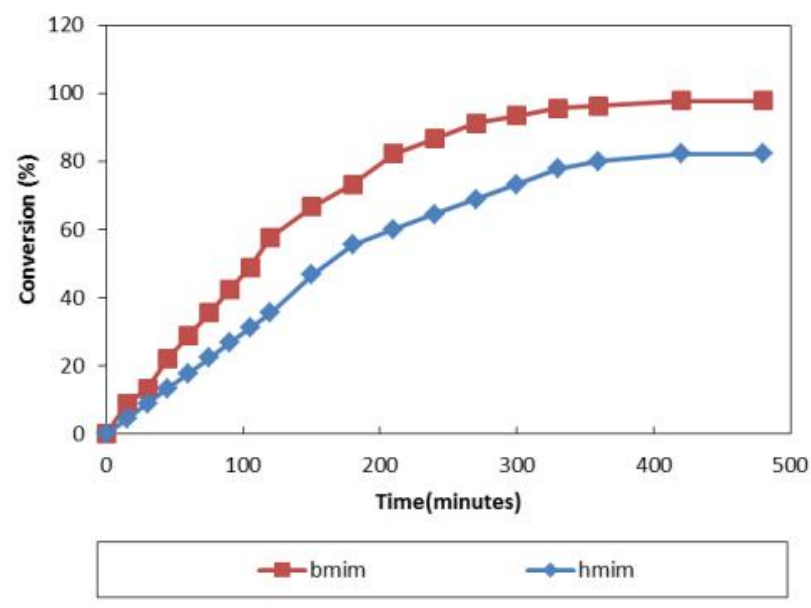

Figure 1. Effect of different IL catalyst on the esterification of SUCO with ethanol. Reaction conditions: $5 \mathrm{wt} \%$ of IL catalysts, molar ratio of ethanol: $\mathrm{SUCO}=12: 1,70^{\circ} \mathrm{C}, 450 \mathrm{rpm}$. lowers the hydroxylation and limiting the electrophilic attack by the acid. Increasing number of carbon atoms will also decrease the polarity consequently lowering the miscibility of the IL with the ester. So, decreasing alkyl chain will increase the reaction efficiency. Since $\mathrm{BMIMHSO}_{4}$ showed the best catalytic performance as compared to $\mathrm{HMIMHSO}_{4}$, it was used for further experimental work.

\subsubsection{The effect of different type of alcohol}

Three types of alcohol i.e. ethanol, propanol and n-butanol, has been evaluated to study the influence of alkyl chain alcohol on the esterification reaction. The experiment was conducted at $70{ }^{\circ} \mathrm{C}$ for $8 \mathrm{~h}$ using $5 \mathrm{wt} \% \mathrm{BMIMHSO}_{4}$ as the catalyst. As shown in Figure 2, the conversion decreases as the alcohol carbon number increases from $98 \%$ to $84 \%$. This could be due to better miscibility of fatty acid and alcohols with alkyl chain in homogeneous system. Probably the presence of a double bond in the alkyl chain increases the miscibility of fatty acid and as a result the alcohol has more chance to attack the carbonyl group. The electron donating ability of alkyl group toward the hydroxyl group increases with increasing the alkyl chain of alcohol thus lowers the hydroxylation and limiting the electrophilic attack by the acid. Increasing number of carbon atoms in linear alcohols will also decrease the alcohol polarity consequently lowering the miscibility of alcohol and SUCO. Besides that, the conversion of FFA using ethanol was higher than propanol and n-butanol because mass transfer problems were reduced due to the higher solubility of triglyceride molecules in

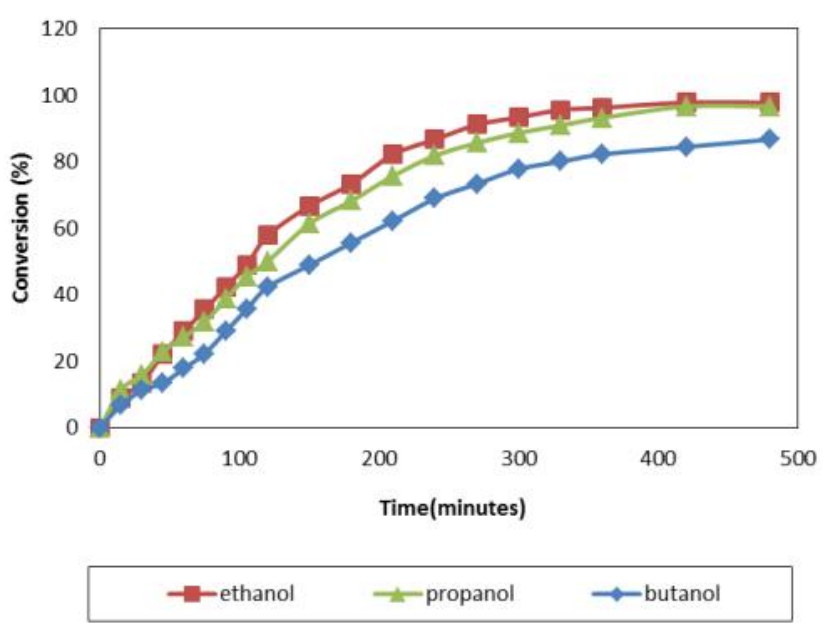

Figure 2. Effect of different type of alcohol on BMIMHSO $_{4}$-catalyzed esterification of SUCO. Reaction conditions: $5 \mathrm{wt} \% \mathrm{BMIMHSO}_{4}$, molar ratio of ethanol: $\mathrm{SUCO}=12: 1,70^{\circ} \mathrm{C}, 450 \mathrm{rpm}$ 
ethanol. This was an agreement with the literature reported earlier by Aghabarari et al. [22] and Ghiaci et al. [23]. Lastly, a further increase in the number of carbon atoms in the alkyl chain resulted in a decrease in the conversion, probably due to steric hindrance restricting the attack of propanol and n-butanol at the carbonyl groups of the triglyceride. The steric component affecting the reactivity is perhaps the decisive factor for acid-catalyzed esterification. Steric hindrance increases with molecular size, inducing electronic repulsion between nonbonded atoms of reacting molecules. This repulsive hindrance lowers electron density in the intermolecular region and disturbs bonding interactions. Thus, as the alkyl chain increases, its steric effect increases as well. Increasing the steric effect will decrease the conversion of FFA. Therefore, ethanol was used as an alcohol for further research.

\subsubsection{Effect of type of stirrer on the esterification of SUCO}

Mixing is one of the important factors that affect the performance of esterification reaction, due to the partial miscibility of oils and alcohol resulting from the polar and non-polar nature of both reactants respectively. The immiscibility of ethanol and SUCO leads to a mass transfer resistance in the esterification reaction. The triglyceride mass transfer limitation is due to the small available active specific catalyst surface, which is mainly covered by adsorbed molecules of ethanol. Influence of mass transfer on the esterification reaction may be observed through temperature, molar ratio and mixing variation as the use of different mixing methods results in different conversions. For the commercialization purpose, mechanical stirrer was used as the production scale was high. But for the small scale study, magnetic stirrer is more convenient as it is easy to handle. For the preliminary stage, two types of stirrer have been evaluated, i.e. magnetic and mechanical stirrer, to investigate the difference in terms of FFA conversion. The reaction was done at the same speed which is $450 \mathrm{rpm}$ to identify the influence of mass transfer resistance. $450 \mathrm{rpm}$ was chosen in this work as it is high enough to mixed approximately $200 \mathrm{ml}$ solution and reduce the mass transfer resistance.

Figure 3 shows the effects of type of stirrer on the conversion of SUCO into biodiesel. It shows that the application of magnetic stirrer and mechanical stirrer did not significantly affect the conversion of FFA. At the same experimental condition, the maximum conversion achieved for both type of stirrer was $98 \%$. The stirring speeds used were high enough to offset the mass transfer resistance. It can be concluded that different types of stirrer were not affect the rate of reaction. As both of the stirrer showed the same performance, magnetic stirrer was chosen for further experimental work as it is suitable for the small scale reaction and can help to reduce the production cost $[1,8,24$, $25]$.

3.2.4. The effect of reaction temperature on the esterification of SUCO with ethanol

Reaction temperature is an important parameter for the esterification of SUCO with ethanol, with higher temperatures always leading to faster rates, together with a shift in the esterification reaction equilibrium towards the product. In order to explore the effect of temperature on the reaction and to find the optimum reaction temperature, the $\mathrm{BMIMHSO}_{4}$ catalyzed esterification of SUCO with ethanol was carried out at different temperatures (338, 343 , and $348 \mathrm{~K}$ ). The results obtained are illustrated in Figure 4.

As is evident from the data depicted in Figure 4 , in a certain range of time for the esterification reaction, the reaction rate clearly increase with an increase in reaction temperature. However, there is usually no substantial improvement in the product conversion when the reaction temperature increased further. This results was in agreement with Aghabarari et al. [22] and Ghiaci et al. [23]. At reaction temperatures below than $348 \mathrm{~K}$, the conversion

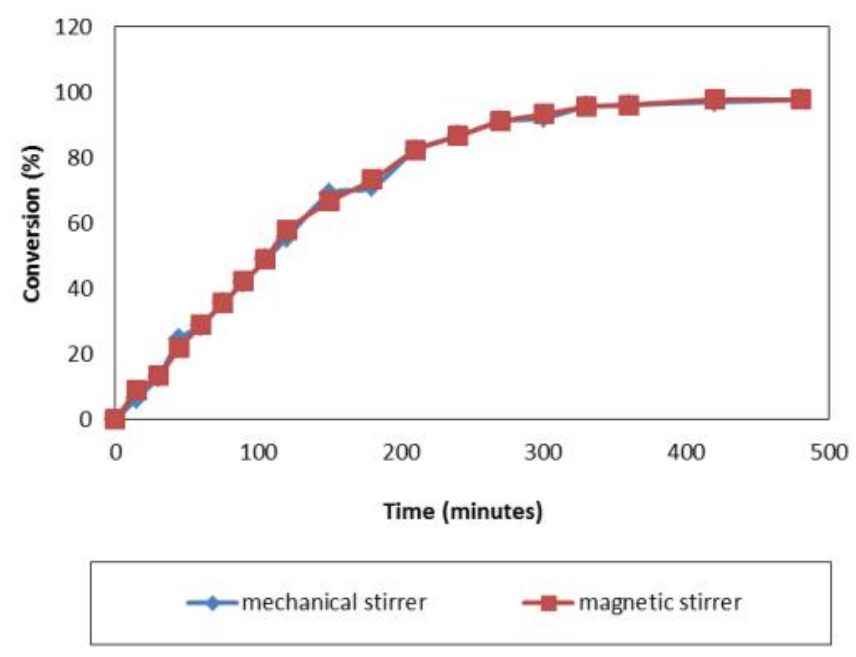

Figure 3. Effect of type of stirrer on the esterification reaction. Reaction conditions: $5 \mathrm{wt} \%$ $\mathrm{BMIMHSO}_{4}$, molar ratio of ethanol: SUCO $=12: 1$, $70{ }^{\circ} \mathrm{C}, 450 \mathrm{rpm}$ 
was significantly increased with the increase of reaction temperature. FFA conversion of $98 \%$ was achieved at a reaction temperature of 343 $\mathrm{K}$ in $7 \mathrm{~h}$ reaction time. Further increase of the reaction temperature $(348 \mathrm{~K})$ did not lead to a significant improvement in the product conversion, indicating that the reaction was close to equilibrium $[8,22]$. However, the time taken to achieve equilibrium when operate the reaction at $348 \mathrm{~K}$ was shorter than $343 \mathrm{~K}$ which is $6 \mathrm{~h}$. Increasing the temperature increases the reaction rates because of the disproportionately large increase in the number of high energy collisions. Rate of reaction depends mainly on the activation energy. The lower it is, the quicker the reaction proceeds. Increasing the temperature decreases the activation energy. Thus, the rate of reaction increases as illustrated in Figure 4. Taking the energy consumption and the product conversion into account, $343 \mathrm{~K}$ was selected as the optimum reaction temperature for the esterification of UCO with ethanol.

\subsubsection{Effect of molar ratio of ethanol to SUCO} on the esterification of SUCO

An excess of reactant ethanol is necessary for the esterification of FFA because it can increase the rate of ethanolysis. Basically, esterification reaction requires one mole of alcohol for each mole of FFA. However, practically it needs higher ratio than the stoichiometric ratio to drive the reaction forward. In order to study the effect of the molar ratio on FFA esterification, the reaction experiments were conducted at two different molar ratios which are 6:1 and

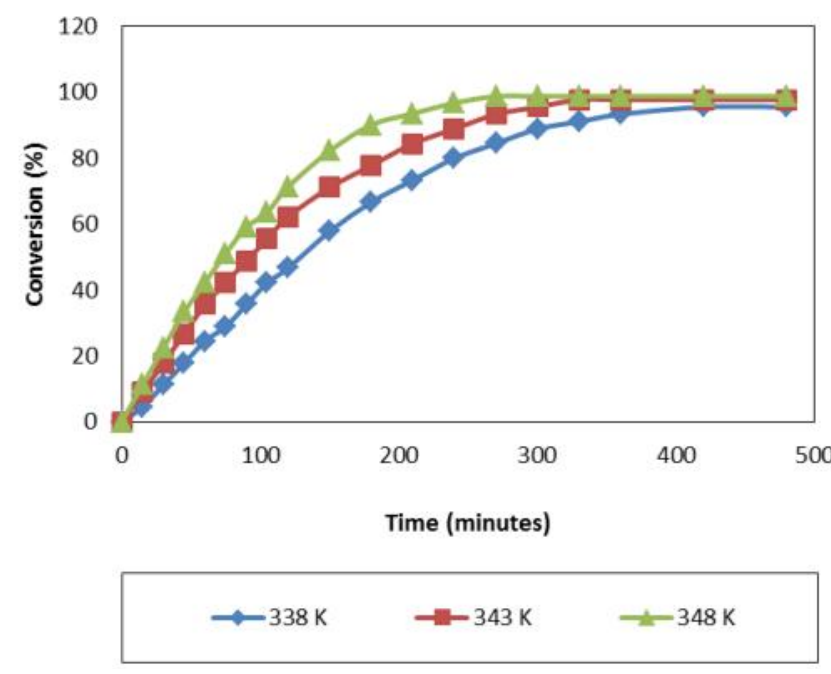

Figure 4. Effect of reaction temperature on $\mathrm{BMIMHSO}_{4}$-catalyzed esterification of SUCO with ethanol. Reaction conditions: $5 \mathrm{wt} \% \mathrm{BMIMHSO}_{4}$, molar ratio of ethanol: $\mathrm{SUCO}=12: 1,450 \mathrm{rpm}$
12:1. The result on FFA conversion obtained versus the molar ratio of the ethanol to oil is shown in Figure 5. During the reaction, the concentration of $\mathrm{BMIMHSO}_{4}$ was fixed at 5 wt $\%$ with $70{ }^{\circ} \mathrm{C}$ reaction temperature and 450 rpm agitation speed. The reaction time was set at $480 \mathrm{~min}$.

The result indicated that the conversion was increased from 94 to $98 \%$ with an increase in the ethanol: oil molar ratio, reaching maximum value at $12: 1$. Both of the molar ratios show a good conversion. However, the higher amount of ethanol, show a better FFA conversion $[8,16,26]$. Excess ethanol is required not only to shift the equilibrium toward and forward direction but also to wash away the active sites. The high amount of ethanol promoted the formation of ethoxy species on the catalyst surface, leading to a shift in the equilibrium in the forward direction in the reaction mixture. Thus, it increases the conversion of FFA. This was an agreement with the literature, since the esterification reaction is reversible and an excess of ethanol contribute to the esterification of SUCO [23]. In this work, the molar ratio $12: 1$ was taken as the optimal ratio to avoid needless rising in the operational expenses by increasing reactor size and increasing the purification step.

\subsubsection{The effect of reaction time on the esterification of SUCO with ethanol}

Reaction time is also an important factor influencing the esterification reaction. Generally, with an increase in reaction time, the reaction

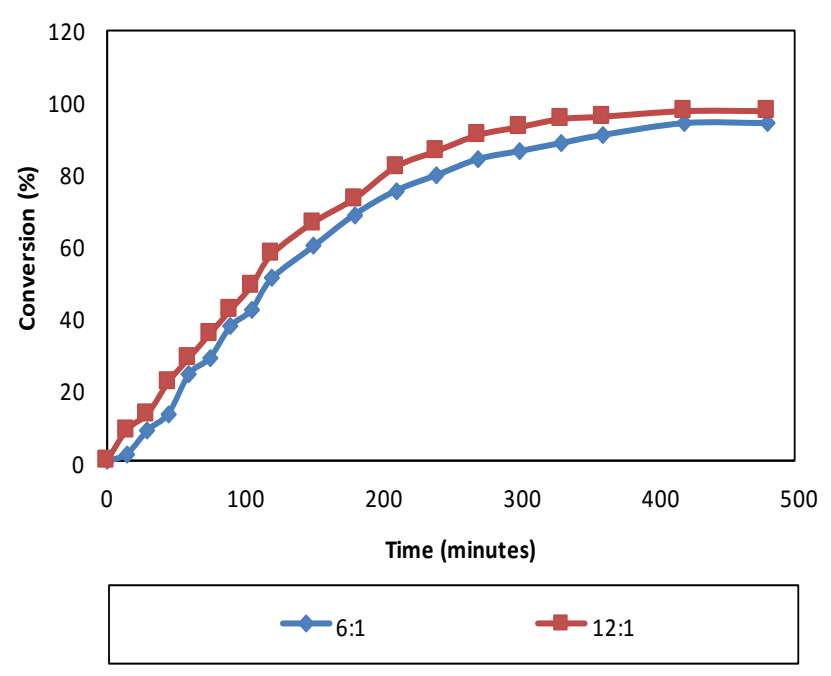

Figure 5. Effect of molar ratio of ethanol to SUCO on the esterification reaction. Reaction conditions: $5 \mathrm{wt} \% \mathrm{BMIMHSO}_{4}, 70{ }^{\circ} \mathrm{C}, 450 \mathrm{rpm}$ 
equilibrium shifts gradually to the products, and the conversion is enhanced. Reaction time mostly depends on the amount of catalyst, alcohol being introduced to the system and operating temperature. Reaction with shorter time to reach equilibrium conversion is better compared to those who are taking way too long to reach equilibrium [5, 7]. To find the optimal reaction time for the esterification, the time course of the reaction was plotted, as depicted in Figure 6.

Figure 6 shows a plot of FFA conversion versus reaction time for the following reaction condition; $5 \mathrm{wt} \% \mathrm{BMIMHSO}_{4}, 12: 1$ molar ratio of ethanol to $\mathrm{SUCO}, 70{ }^{\circ} \mathrm{C}$ reaction temperatures with the agitation speed of $450 \mathrm{rpm}$. As can be seen in Figure 6, the esterification process could be divided into three phases. In the first phase, the substrate SUCO reacted rapidly with the excess ethanol, and more than $67 \%$ SUCO was converted within $3 \mathrm{~h}$. In the second phase, the reaction rate gradually increased in the period from 4 to $7 \mathrm{~h}$, and a relatively high conversion of FFA (98\%) was obtained at a reaction of $7 \mathrm{~h}$. In the third phase, the esterification reaction moved to equilibrium stage, and the conversion showed no improvement at this extended reaction time. It was found that when the reaction time exceeds the time required to attain equilibrium, the conversion does not increase significantly with increasing reaction time, in agreement reported by Aghabarari et al. [22] and Ullah et al. [26]. Therefore, the optimum time needed to produce the highest conversion at optimum temperature and molar ratio is $7 \mathrm{~h}$.

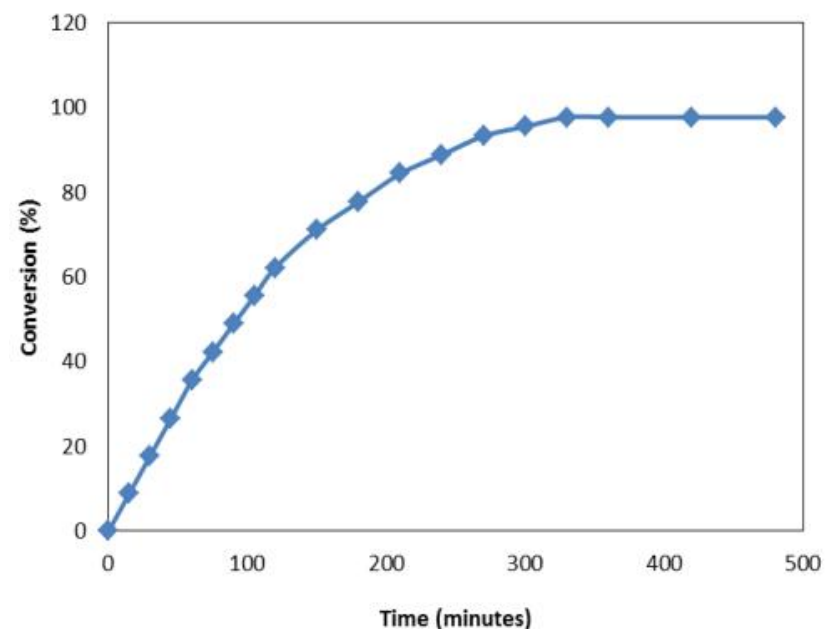

Figure 6. Time course of the $\mathrm{BMIMHSO}_{4}$ catalyzed esterification of SUCO with ethanol. . Reaction conditions: $5 \mathrm{wt} \% \mathrm{BMIMHSO}_{4}$, molar ratio of ethanol: $\mathrm{SUCO}=12: 1,70^{\circ} \mathrm{C}, 450 \mathrm{rpm}$

\section{Conclusions}

Two types of ionic liquid was compared for the esterification of SUCO for the preparation of feedstock for transesterification reaction. There are three main stages involved to determine the optimum condition for the best catalyst. Firstly, two types of ILs, $\mathrm{HMIMHSO}_{4}$ and $\mathrm{BMIMHSO}_{4}$ were compared. The results show that both of the catalysts potential to be used as the catalyst in esterification reaction. The conversion of $\mathrm{BMIMHSO}_{4}$ was $98 \%$ which was higher than $\mathrm{HMIMHSO}_{4}$, which approximately $82 \%$ conversion and thus, $\mathrm{BMIMHSO}_{4}$ was selected for further experimental work. The experimental work continued with the second stage by comparing the performance of different type of alcohol. It showed that the esterification of fatty acids using ethanol gives a better performance compared to propanol and nbutanol. This is due to the miscibility of ethanol with the SUCO is higher as it has lowest alkyl chain than propanol and n-butanol. By using $\mathrm{BMIMHSO}_{4}$ and ethanol, a few variables has been varied at the final stage (i.e; type of stirrer, temperature, molar ratio and reaction time) to find the optimum condition. Therefore, by using $\mathrm{BMIMHSO}_{4}$, ethanol and magnetic stirrer, the optimized reaction conditions for the process are 12:1 ethanol: SUCO mole ratio, $7 \mathrm{~h}$ reaction time and $343 \mathrm{~K}$. From the results, it was concluded that $\mathrm{BMIMHSO}_{4}$ shows an excellent catalytic performance to be used as catalyst in the esterification of highly acidified oil due to lower alkyl chain and better miscibility towards alcohol. $\mathrm{BMIMHSO}_{4}$ also has the potential to produce low cost biodiesel from low cost feedstocks in addition to being environmentally friendly.

\section{Acknowledgment}

The authors would like to express their sincere gratitude to Universiti Malaysia Pahang for the Research University Grant (RDU 130311) and the financial support from GRS 1403159 .

\section{References}

[1] Li, Y., Hu, S., Cheng, J., Lou, W. (2014). Acidic Ionic Iquid-Catalyzed Esterification of Oleic Acid for Biodiesel Synthesis. Chinese Journal of Catalysis, 35(3): 396-406.

[2] Sheehan, J., Camobreco, V., Duffield, J., Graboski, M., Shapouri, H. (2000). Overview of Biodiesel and Petroleum Diesel Life Cycles. US: National Renewable Energy Lab, Golden, CO, 30: 1399-1405. 
[3] Vasudevan, P., Fu, B. (2010). Enviromentally Sustainable Biofuels: Advances in Biodiesel Research. Waste Biomass Valorization, 1(1): 47-63

[4] Somnuk, K., Smithmaitrie, P., Prateepchaikul. (2013). Two-stage Continuous Process of Methyl ester from High Free Fatty Acid Mixed Crude Palm Oil using Static Mixer Coupled with High-intensity of Ultrasound. Energy Conversion and Management, 75: 302310.

[5] Costa, J.F., Almeida, M.F., Alvim-Ferraz, M. C.M., Dias, J.M. (2013). Biodiesel Production using Oil from Fish Canning Industry Waste. Energy Conversion and Management, 74: 1723.

[6] Somnuk, K., Smithmaitrie, P., Prateepchaikul. (2013). Optimization of Continuous AcidCatalyzed Esterification for Free Fatty Acids Reduction in Mixed Crude Palm Oil using Mixer Coupled with High-Intensity Ultrasonic Irradiation. Energy Conversion and Management, 68: 193-199.

[7] Ong, H.C., Silitonga, A.S., Masjuki, H.H., Mahlia, T.M.I., Chong, W.T., Boosroh, M.H. (2013). Production and Comparative Fuel properties of Biodiesel from Non-Edible Oils: Jatropha Curcas, Sterculia Foetida and Ceiba Pentandra. Energy Conversion and Management, 73: 245-255.

[8] Zhang, L., Xian, M., He, Y., Li, L., Yang, J., Yu, S., et al. (2009). A Brønsted Acidic Ionic Liquid as an Efficient and Environmentally Benign Catalyst for Biodiesel Synthesis from Free fatty Acids and Alcohols. Bioresource Technology, 100(19): 4368-4373.

[9] López, D.E., Goodwin, Jr.J.G., Bruce, D.A., Furuta, S. (2008). Esterification and Transesterifcation using Modified-Zirconia Catalyst. Applied Catalyst A: General, 339(1): 7683.

[10] Thiruvengadaravi, K.V., Nandagopal, J., Baskaralingam, P., Sathya, S.B.V., Sivanesan, S. (2012). Acid-catalyzed Esterification of Karanja (Pongamia Pinnata) Oil with High Free Fatty Acids for Biodiesel Production. Fuel, 98: 1-4.

[11] Noshadi, I., Amin, N.A.S., Pamas, R.S. (2012). Continuous Production of Biodiesel from Waste Cooking Oil in a Reactive Distillation Column Catalyzed by Solid Heteropolyacid: Optimization using Response Surface Methodology (RSM). Fuel, 94: 156-164.

[12] Gan, S., Ng, H.K., Chan, P.H., Leong, F.L. (2012). Heterogeneous Free Fatty Acids Esterification in Waste Cooking Oil using IonExchange Resins. Fuel Process Technology, 102: 67-72.
[13] Vafaeezadeh, M., Hashemi, M.M. (2014). Efficient Fatty Acid Esterification Using Silica Supported Brønsted Acidic Ionic Liquid Catalyst: Experimental Study and Draft Modeling. Chemical Engineering Journal, 250: 3541.

[14] Fang, D., Yang, J., Jiao, C. (2011). Dicationic Ionic Liquids as Environmentally Benign Catalysts for Biodiesel Synthesis. ACS Catalysis, 1(1): 42-47.

[15] Guo, F., Fang, Z., Tian, X-F., Long, Y-D., Jiang, L-Q. (2011). One-Step Production of Biodiesel from Jatropha Oil with High-Acid Value in Ionic Liquids. Bioresource Technology, 102(11): 6469-6472.

[16] Elsheikh, Y.A., Man, Z., Bustam, M.A., Yusup, S., Wilfred, C.D. (2011). Bronsted Imidazolium Ionic Liquids: Synthesis and Comparison of their Catalytic Activities as PreCatalyst for Biodiesel Production Through Two Stage Process. Energy Conversion and Management, 52(2): 804-809.

[17] Gerhard Knothe, J. V. G. and Krahl Jurgen. (2004). The biodiesel handbook. AOCS Press.

[18] Lotero, E., Liu, Y.J., Lopez, D.E., Suwannakaran, K., Bruce, D.A., Goodwin, J.G. (2005). Synthesis of biodiesel via acid catalysis. Industrial \& Engineering Chemistry Research, 44(14): 5353-5363.

[19] Diego, T.D., Manjón, A., Lozano, P., Iborra, J.L. (2011). A Recyclable Enzymatic Biodiesel Production Process In Ionic Liquids. Bioresource Technology, 102(10): 6336-6339.

[20] Ha, S.H., Lan, M.N., Lee, S.H., Hwang, S.M., Koo, Y-M. (2007). Lipase-Catalyzed Biodiesel Production From Soybean Oil In Ionic Liquids. Enzyme and Microbial Technology, 41(4): 480-483.

[21] De Azevedo, R.G., Esperanca, J.M.S.S., Szydlowski, J., Visak, Z.P., Pires, P.F., Guedes, H.J.R., Rebelo, L.P.N. (2005). Thermophysical and Thermodynamic Properties of Ionic Liquids Over an Extended Pressure Range: [bmim][NTf2] and [hmim][NTf2]. The Journal of Chemical Thermodynamics, 37(9): 888-899.

[22] Aghabarari, B., Dorostkar, N., Ghiaci, M., Amini, S.G., Rahimi, E., Martinez-Heurta, M.V. (2014). Esterification of Fatty Acids by New Ionic Liquids as Acid Catalysts. Journal of Taiwan Institute of Chemical Engineers, 45(2): 431-435.

[23] Ghiaci, M., Aghabarari, B., Habibollahi, S., Gil, A. (2011). Highly Efficient Brønsted Acidic Ionic Liquid-Based Catalysts for biodiesel Synthesis from Vegetable Oils. Bioresource Technology, 102(2): 1200-1204 
[24] D'Oca, M.G.M., Soares, R.M., de Moura, R.R., Granjão, V.F. (2012). Sulfamic acid: An Efficient Acid Catalyst for Esterification of FFA. Fuel, 97: 884-886.

[25] Barros, S.D.T., Coelho, A.V., Lachter, E.R., Gil, R.A.S.S., Dahmouche, K. (2013). Esterification of Lauric Acid with butanol over Mesoporous Materials. Renewable energy, 50: 585-589.
[26] Ullah, Z., Bustam, M.A., Man, Z. (2015). Biodiesel Production from Waste Cooking Oil by Acidic Ionic Liquid as a Catalyst. Renewable Energy, 77: 521-526

Selected and Revised Papers from The International Conference on Fluids and Chemical Engineering (FluidsChE 2015) (http://fluidsche.ump.edu.my/index.php/en/) (Malaysia, 25-27 November 2015) after Peer-reviewed by Scientific Committee of FluidsChE 2015 and Reviewers of BCREC 